\title{
Chemical Reactivity of Supported Gold III. Atomic Binding and Coordination of Gold from X-Ray Absorption Fine Structure Spectroscopy ${ }^{I}$
}

\author{
I. W. BAssI \\ Istituto Donegani, Novara, Italy \\ F. W. LYTtE \\ Boeing Aerospace Company, Seattle, Washington \\ AND \\ G. Parravano ${ }^{2}$ \\ Department of Chemical Engineering, University of Michigan, Ann Arbor, Michigan 48104
}

Received September 26, 1975

\begin{abstract}
Preparations of $\mathrm{Au}$ and $\mathrm{Pt}$ supported on $\mathrm{Al}_{2} \mathrm{O}_{3}, \mathrm{MgO}$, and $\mathrm{SiO}_{2}$ were subjected to analysis by extended X-ray absorption fine structure spectroscopy (EXAFS). The samples contained 0.20 , 5.00 , and $8.00 \mathrm{wt} \% \mathrm{Au}$, and $5.00 \mathrm{wt} \% \mathrm{Pt}$. Metal dispersion ranged between 0.3 to $45 \%$. Anisotropic growth was detected in the larger particles. The $L_{\text {III }} \mathrm{X}$-ray absorption coefficient was normalized to the same atom basis and Fourier transformed to yield the radial structure function for each preparation. From bond distance comparison with reference materials, assignments were made to specific peaks of the radial structure function.

The analysis of the results showed that the metals were present in two distinct phases: metallic with coordination and metal-to-metal distance characteristic of bulk $\mathrm{Au}$, and $\mathrm{Pt}$, (partieulate phase), and a highly disperse one (dissolved phase). It was concluded that the latter consisted of metal atomically dispersed, or condensed in small, flat clusters of a few atoms. It was further estimated that the majority of $\mathrm{Au}$ and $\mathrm{Pt}$ was present in the highly disperse form, i.e., $60 \%$ for $\mathrm{Au}$ and $86 \%$ for $\mathrm{Pt}$. Au atoms did not simply substitute $\mathrm{Mg}$ in the $\mathrm{MgO}$ matrix to form the dissolved $\mathrm{Au}-\mathrm{MgO}$ phase and they carried an average charge +1 .
\end{abstract}

In previous researches on supported $\Lambda u$ microparticles it was found that the onset of chemical reactivity in Au metal was dependent upon the nature of the support, the size of the microparticles and their preparation method (1). In hydrogen (2) and oxygen (1) transfer reactions, the activity of supported $\mathrm{Au}$ was found to be

1 Previous articles in this series: $J$, Catal. 18, 200, 320 (1970).

${ }^{2}$ To whom all queries about this paper should be addressed. comparable to that of Pt. Supported Au has already achieved a position of commercial importance in the process industry as a catalytic partner in industrial chemical processes (3). Despite the interesting catalylic performance and increasing industrial applications, it has not yet been possible to clarify the physical and chemical phenomena associated with the size and the morphology of supported $\mathrm{Au}$ particles whose reactivity stands in drastic contrast to the inertness of the massive metal. 
From a preliminary review of the structural and morphological problem of supported $\mathrm{Au}$ it was concluded that three microparticle parameters needed a thorough inspection for their possible key role in controlling the state of the metal and therefore its reactivity in the supported preparations, namely: the $\mathrm{Au}-\mathrm{Au}$ distance, the coordination around an $\mathrm{Au}$ atom (number and nature of nearest neighbors), and the electron binding energy of $\mathrm{Au}$. In this direction, it appeared to us that X-ray absorption fine structure spectroscopy (EXAFS) could successfully contribute to the derivation of a realistic model for the $\mathrm{Au}$ system that could include the role of the above parameters. EXAFS is eminently suited to explore the surroundings of the absorbing $\mathrm{Au}$ atom and to provide the radial structure function centered on the atom of interest. This function gives direct information on the nature and number of coordinating atoms (4). Under favorable circumstances, from EXAFS it is also possible to derive energy shifts in the absorption edge relative to the bulk metal that are indicative of the nature of the binding of the atoms. Although the determination of the electron binding energy through EXAFS is not direct and detailed as through ESCA, the possibility of the simultaneous measurement of the radial structure function and of the electron binding energy on the same sample and under exactly similar experimental conditions provides an important simplification and a powerful tool to increase the consistency of the measurements.

\section{EXPERIMENTAL METHODS}

Materials. Three samples of supported $\mathrm{Au}$ were investigated: A 1141, Au on $\eta-\mathrm{Al}_{2} \mathrm{O}_{3}$ (Davison, surface area $230 \mathrm{~m}^{2} / \mathrm{g}$ ), prepared by $\mathrm{Al}_{2} \mathrm{O}_{3}$ impregnation with aqueous solution of $\mathrm{HAuCl}_{4} \cdot 3 \mathrm{H}_{2} \mathrm{O}$ (Baker Co.), followed by reduction with $2 \%$ oxalic acid solution at $40^{\circ} \mathrm{C}$, filtered, washed, dried, and heated at $350^{\circ} \mathrm{C}, 2 \mathrm{hr}, 0.1$
Torr; A 1211, and A $1241 \mathrm{Au}$ on $\mathrm{MgO}$ (reagent grade, surface area $18 \mathrm{~m}^{2} / \mathrm{g}$ ), preparation similar to that employed for A 1141.

Materials employed as references for $\mathrm{Au}$ were: $\mathrm{Au}$ foil (2.5 thick, rolled from $99.9 \% \mathrm{Au}$ ); $\mathrm{HAuCl}_{4} \cdot 3 \mathrm{H}_{2} \mathrm{O}$ (Baker); $\mathrm{Au}_{2} \mathrm{O}_{3}$ (Research Organic/Inorganic Chemical Corp.). Since Pt and Au are adjacent elements in the periodic table similar EXAFS properties should be expected (absorption edge, phase shift, magnitude normalization, etc.). Pt provides also an interesting comparison to a related supported catalyst system. It was then decided to include supported $\mathrm{Pt}$ as a reference material. $\mathrm{Pt}$ preparations employed were as follows: $5 \%$ Pt on Cab-O-Sil, prepared by impregnation from a $\mathrm{H}_{2} \mathrm{PtCl}_{6}$ solution followed by reduction by $\mathrm{H}_{2}$ at $500^{\circ} \mathrm{C}$. $\mathrm{PtCl}_{2}$ (Matthey Bishop); $\alpha-\mathrm{PtO}_{2}$ prepared according to a literature method (5) and $\mathrm{Pt}$ foil (2.5 thick, 99.9\% Pt).

Equipment. X-Ray absorption experiments were carried out with an X-ray tube with an $\mathrm{Ag}$ target, a $\mathrm{LiF}$ monochromator and a Xe filled proportional counter.

Procedure. Samples were mounted within a dry box into a cell with Mylar windows, the cell was pumped down to the $10^{-6}$ Torr and cooled to $77^{\circ} \mathrm{K}$ for the duration of the X-ray measurements. Approximately 10 passes through each absorption edge (20 passes for A 1211) were averaged to obtain the desired statistics. The $L_{\text {III }}$ absorption edge was measured for both metals. The phase shift, which appears in the expression of the radial structure function and it is related to electron vacancies in the absorbing atom, was derived from standard materials following a procedure already described (4). For the first coordination shell of the standard material one has (4)

$$
\frac{\operatorname{Mag}_{s} \cdot r_{1 s}^{2}}{N_{1 s}}=C=\text { constant, }
$$

where $\operatorname{Mag}_{\mathrm{s}}$ is the magnitude of the first 
peak of the Fourier transform of the EXAFS data of the standard material, $r_{1 s}$ its distance ( $\AA$ ) (after correction to take into account the phase shift) from the absorbing atom $(r=0)$, and $N_{1 s}$ is the coordination number relative to the first shell. Once $C$ is defined for the standard material, the coordination number, $N_{1}$, for the first shell of the unknown material is given by:

$$
N_{1 x}=\frac{\operatorname{Mag}_{x} \cdot r_{1 x}^{2}}{C}
$$

where $\operatorname{Mag}_{x}$ and $r_{1 x}$ have the same meaning as before but are now the values defined for the unknown material. Data were normalized to separate EXAFS information from the background and reduced thus to a per atom basis (4). The normalized EXAFS data for the reference materials and the supported Au samples were Fourier transformed to obtain structure functions containing information on interatomic distances and coordination numbers (4).

\section{Supported Gold and Reference Materials Characterization}

X-Ray diffraction patterns of supported $\mathrm{Au}$ preparations showed peaks of both metallic $\mathrm{Au}$ and support material. Particle size of supported Au and Pt obtained from X-ray line broadening is reported in Table 1 together with sample composition (by atomic absorption).

Since A 1141 presented very sharp X-ray diffraction lines, measurements on the side of the unit cell were performed on this sample. The value found was $4.0799 \AA$, while that for bulk metallic gold is $4.0786 \AA$ (6). This indicates that $\mathrm{Au}$ particles had a well defined metallic structure. $\mathrm{Au}$ particle size was measured for this sample on the (200), (400), (111), and (222) lines. It was found that in the direction $\perp$ to the (111) plane particle size was $2200 \AA$, while in the direction $\perp$ to the (200) plane was $1300 \AA$. This is an indica-
TABLE 1

Particle Diameter, ${ }^{a} D$, Dispersion of Supported Au and Pt Preparations

\begin{tabular}{lccc}
\hline Sample & $\begin{array}{c}\text { Metal } \\
(\text { wt\%) }\end{array}$ & $D(\AA)$ & $\begin{array}{c}\text { Dispersion } \\
(\%)\end{array}$ \\
\hline A 1241 & 5.00 & 100 & 9 \\
A 1141 & 8.00 & $1300-2200$ & 0.6 \\
A 1211 & 0.20 & 20 & 45 \\
Pt & 5.00 & 50 & 18 \\
\hline
\end{tabular}

a Caloulated assuming spherical shape.

tion that particle growth did not occur isotropically-faster growth took place in the direction $\perp$ to the octahedral (111) plane. It is likely that the anisotropy in particle growth, which is somewhat surprising for particles of this size, has also contributed to a nonstatistical distribution of crystal planes at the surface.

The metallic $\mathrm{Au}$ foil and $\mathrm{HAuCl}_{4} \cdot 3 \mathrm{H}_{2} \mathrm{O}$ were of known crystal structure; however, $\mathrm{Au}_{2} \mathrm{O}_{3}$ was of dubious crystallinity. Its $X$-ray diffraction showed only a trace of broad $\mathrm{Au}$ peaks. The problem of crystallization of $\mathrm{Au}_{2} \mathrm{O}_{3}$ has been discussed previously (7) and the $\mathrm{Au}-\mathrm{O}$ distance of $2.04 \AA$ found by these authors was assumed for the present $\mathrm{Au}_{2} \mathrm{O}_{3}$ sample.

\section{RESULTS}

The oscillatory part of the $L_{\text {III }}$ X-ray absorption coefficient $\chi(K)$ normalized

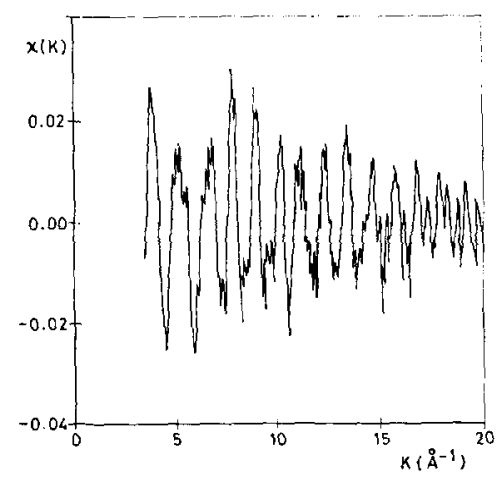

FIG. 1. X-Ray absorption coefficient $\chi(K)$, of metallic $\mathrm{Au}$ plotted vs the photoelectron wave vector, $K$. 


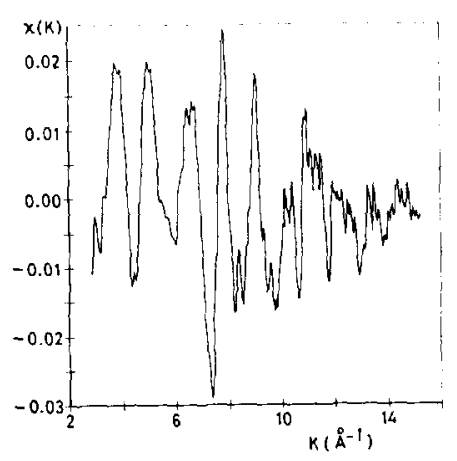

Frg. 2. X-Ray absorption coefficient $\chi(K)$, of $\mathrm{Au}$ in A 1141 plotted vs photoelectron wavevector, $K$.

to the same atom basis of metallic Au, plotted versus the photoelectron wave vector $K$ is reported in Fig. 1. In Figs. 2, 3, and 4, similar plots for A 1141, A 1121, and Pt on Cab-O-Sil are presented. The magnitude of the $K^{3}$ Fourier transform of $\chi(K)$ plotted versus the radial distance from the absorbing atom, $r$ for metallic Au is shown in Fig. 5. This is the EXAFS spectrum of $\mathrm{Au}$. The numbers over the peaks locate the first seven coordination shells of metallic $\mathrm{Au}$. The constant phase shift is clearly noticeable. In Figs. 6 to 12 we report similar pints for $\mathrm{HAuCl}_{4} \cdot 3 \mathrm{H}_{2} \mathrm{O}, \mathrm{Au}_{2} \mathrm{O}_{3}, \mathrm{~A}$ 1241, A 1141, A 1211, metallic Pt and Pt on Cab-O-Sil. Results of the computations for the distances between $\mathrm{Au}$ atoms and those in the first coordination sphere, $r_{1}$, and their coordination number, $N$, are collected in Table 2. The $r_{1}$ distances were corrected

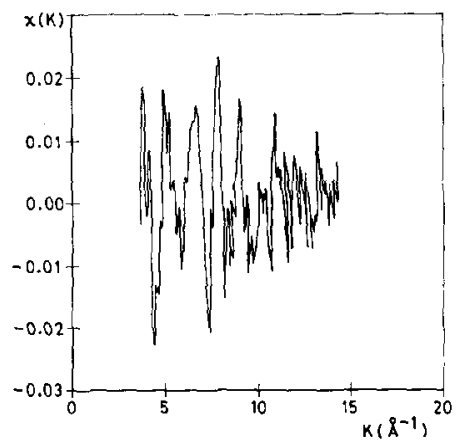

FIG. 3. X-Ray absorption coefficient, $\chi(K)$, of $\mathrm{Au}$ in A 1211 plotted vs photoelectron wavevector, $K$.

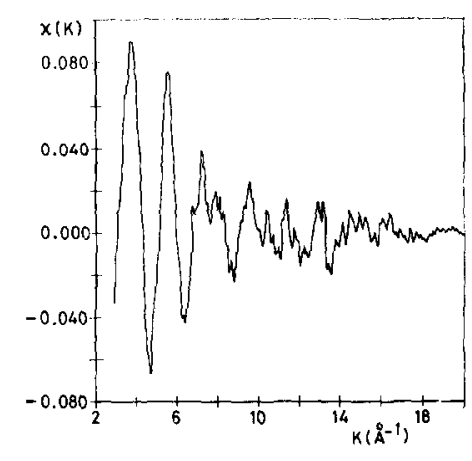

Fig. 4. X-Ray absorption coefficient, $\chi(K)$, of Pt in $\mathrm{Pt}-\mathrm{SiO}_{2}$ plotted vs photoelectron wavevector, $K$.

for the phase shift observed for the reference materials, i.e., $0.15 \AA$ for $\mathrm{Au}-\mathrm{Au}$ and $0.38 \AA$ for $\mathrm{Au}-\mathrm{O}$ and $\mathrm{Au}-\mathrm{Cl}$. For $\mathrm{Pt}-\mathrm{Pt}$ the value is $0.14 \AA$, while for $\mathrm{Pt}-\mathrm{O}, \mathrm{Pt}-\mathrm{Cl}$ $0.33 \AA$. The fact that more than one distance is found for $r_{1}$ in the catalysts indicates that more than one $\mathrm{Au}$ phase is present and the environment is generally complex.

\section{DISCUSSION}

From EXAFS results three separate distances were qualitatively observed for the first coordination shell of $\mathrm{Au}$ in the supported Au preparations (Table 2), a strong $\mathrm{Au}-\mathrm{Au}$ distance varying from 2.89 to $3.08 \AA$ (this variation is larger than the normal error or 0.06 ), and two weaker ones:

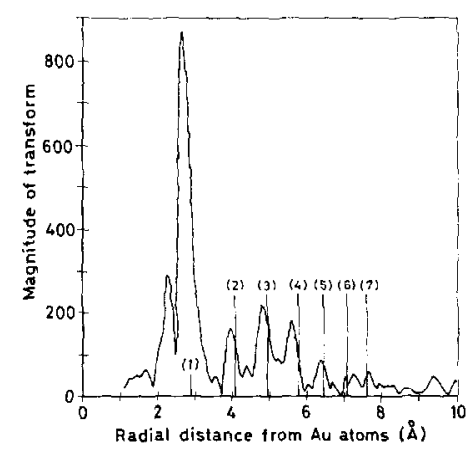

FIa. 5. Magnitude of the $K^{3}$ Fourier transform of $\chi(K)$, plotted vs the radial distance from the absorbing atom, $r^{\prime}$ for metallic Au. The numbers over the peaks locate the first seven coordination shells of metallic Au. 


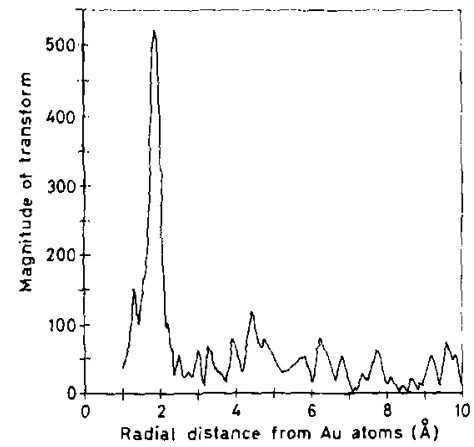

FIG. 6. Magnitude of the $K^{3}$ Fourier transform of $\chi(K)$ vs $r^{\prime}$ for $\mathrm{HAuCl}_{4} \cdot 3 \mathrm{H}_{2} \mathrm{O}$.

2.00 to 2.35 and 1.61 to $1.77 \AA$. The first is assigned to the $A u-A u$ bonding, while the second and the third to $\mathrm{Au} \sim \mathrm{O}$ or $\mathrm{Au}-\mathrm{Cl}$ bonding. These assignments were made strictly by bond distance comparison to standard materials. In A 1211 the $3.75 \AA$ distance probably indicates a second neighbor. The difference between samples A 1241 and $A 1211$ is instructive. Both are supported on $\mathrm{MgO}, \mathrm{A} 1241$ has $100 \AA \mathrm{Au}$ particles, while A 1211 has $20 \AA \mathrm{Au}$ particles. Both show strong metallic Au peaks (Figs. 8 and 10), A 1211 has a longer $\mathrm{Au}-\mathrm{Au}$ distance, which may be evidence of lattice distortion due to interaction with the support. The very strong peak at $1.61 \AA$ on $\mathrm{A} 1211$ compared to $1.77 \AA$ on A 1241 is taken as evidence of more bonding to the support in this more disperse sample. The two additional peaks at 2.00 and $2.30 \AA$ in $\mathrm{A} 1241$ have been

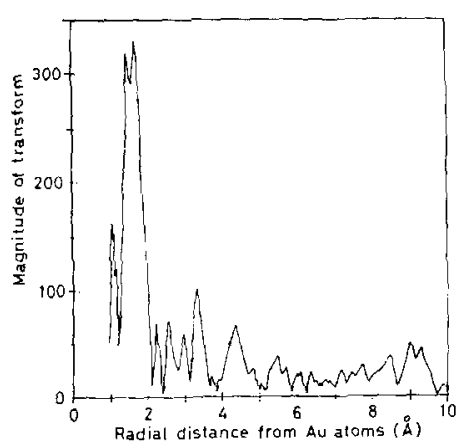

FiG. 7. Magnitude of the $K^{3}$ Fourier transform of $\chi(K)$ vs $r^{\prime}$ for $\mathrm{Au}_{2} \mathrm{O}_{3}$.

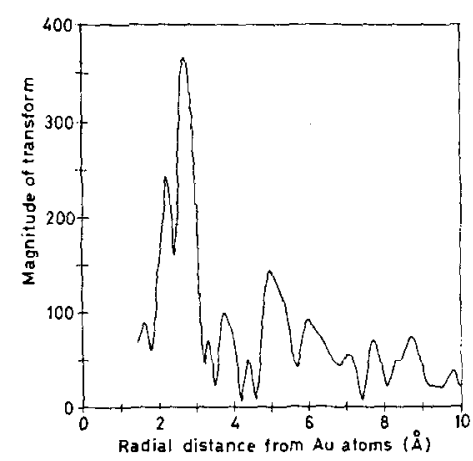

Fig. 8. Magnitude of the $K^{3}$ Fourier transform of $\chi(K)$ vs $r^{\prime}$ for $\mathrm{A} 1241$.

identified with an oxygen distance and the resolution of the electronic $p \rightarrow s$ transition in $\mathrm{Au}$ (4), respectively. The distance at $2.00 \AA$ in $\mathrm{A} 1141$ was assigned to the $\mathrm{Au}-\mathrm{O}$ bond, since from the Fourier transform of the $\mathrm{Au}_{2} \mathrm{O}_{3}$ standard the distance $\mathrm{Au}^{3+}-\mathrm{O}^{2-}$ was determined to be $2.04 \AA$. The twin peak appearing to the left of each major peak, which is most apparent in the Au spectrum (Fig. 5) and is due to the $p \rightarrow d$ and $p \rightarrow s$ electronic transitions (8), has been accounted for in these peak assignments. In addition to the $p \rightarrow s$ effect, the $2.62 \AA$ peak in the Fourier transform of A 1141 (Table 2) may also be assigned to a $\mathrm{Au}^{+}-\mathrm{O}^{2-}$ distance. In fact from the ionic radii (9) one has: $r_{\mathrm{Au}^{+}}+r_{\mathrm{O}^{2-}}$ $=1.37+1.35=2.72 \AA$. The $\mathrm{Au}-\mathrm{Au}$ average coordination of 5 in A 1241 and A 1141 can be used, together with the

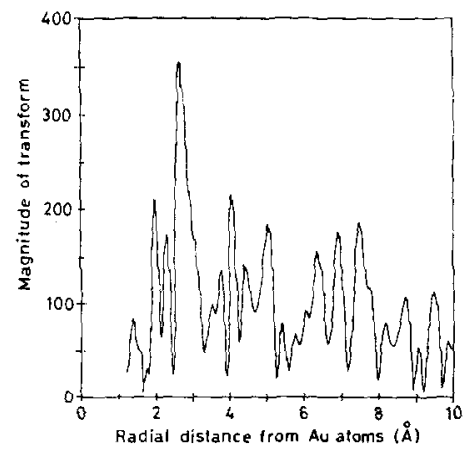

FIa. 9. Magnitude of the $K^{3}$ Fourier transform of $\chi(K)$ vs $2^{\prime}$ for A 1141 . 


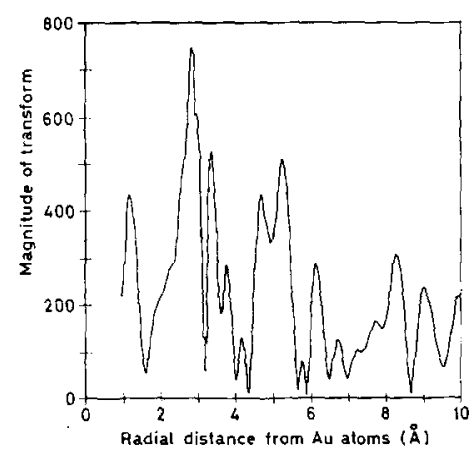

FIa. 10. Magnitude of the $K^{3}$ Fourier transform of $\chi(K)$ vs $r^{\prime}$ for A 1211.

known particle size, to determine the fraction of $\mathrm{Au}$ present in the metallic phase. (The coordination number of about 11 for A 1211 seems to be erroneous, probably due to normalization errors due to low metal concentration. Only the characteristic distances were used in interpreting the results for this sample.) Assuming that it is possible to weight additively the surface and bulk coordination numbers, 6 and 12, respectively, according to the corresponding atom fraction, from the $\mathrm{X}$-ray dispersion results reported in Table 1 one may calculate the average $\mathrm{Au}-\mathrm{Au}$ coordination in each sample. Dividing this average coordination by the number of atoms in the first coordination sphere corresponding to the $\mathrm{Au}-\mathrm{Au}$ distances calculated for each Au preparation (Table

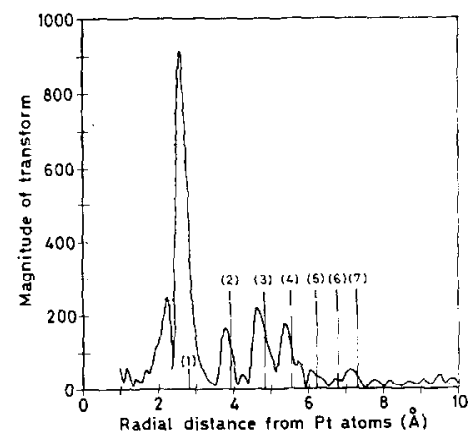

FIG. 11, Magnitude of the $K^{3}$ Fourier transform of $\chi(K)$ vs $r^{\prime}$ for metallic Pt. The numbers over the peaks locate the first seven coordination shells of metallic Pt.

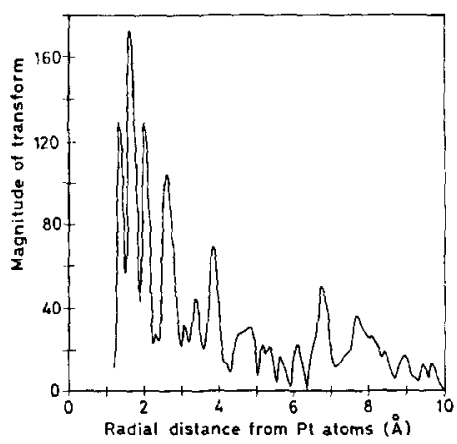

Fig. 12. Magnitude of the $K^{3}$ Fourier transform of $\chi(K)$ vs $r^{\prime}$ for Pt on Cab-O-Sil.

2), the percentage of the total Au present in the condensed metallic phase is obtained. The results of these calculations are collected in Table 3 . The interesting result is that for A 1241 and $\mathrm{A} 1141$ and $\mathrm{Pt}-\mathrm{SiO}_{2}$, only 44,41 , and $14 \%$, respectively, of the metal $\mathrm{Au}$ was present in the metallic phase. To confirm this conclusion an independent

\section{TABLE 2}

Distance, $r_{1}$, and Number of Atoms, $N$, in the First Coordination Sphere of $\mathrm{Au}$ and $\mathrm{Pt}$ in Supported $\mathrm{Au}$ and Pt Preparations and Salts

\begin{tabular}{lccc}
\multicolumn{1}{c}{ Sample } & $r_{1}(\AA)$ & $N$ & Type of atom \\
\hline A 1241 & 1.77 & 0.4 & \\
& 2.35 & 1.8 & O or Cl \\
& 2.89 & 4.6 & $\mathrm{Au}$ \\
$\mathrm{A} 1141$ & 2.00 & 0.5 & $\mathrm{O}$ \\
& 2.62 & 2.6 & \\
& 2.93 & 4.9 & $\mathrm{Au}$ \\
$\mathrm{A} 1211$ & 1.61 & 1.7 & \\
& 3.08 & 11.1 & $\mathrm{Au}$ \\
& 3.75 & 11.3 & $\mathrm{Au}$ \\
$\mathrm{Au} \mathrm{foil}$ & 2.88 & 12 & $\mathrm{Au}$ \\
$\mathrm{HAuCl}_{4} \cdot 3 \mathrm{H}_{2} \mathrm{O}$ & 2.29 & 4 & \\
$\mathrm{Au}_{2} \mathrm{O}_{3}$ & 1.93 & 2 & \\
& 2.12 & 2 & \\
$\mathrm{Pt}$ & 2.77 & 12 & \\
$\mathrm{PtCl}_{2}$ & 2.32 & 4 & \\
$\mathrm{Pt}(5 \mathrm{wt} \%)$ & 1.72 & 0.6 & \\
& 2.03 & 1.2 & $\mathrm{O}$ \\
& 2.38 & 1.2 & $\mathrm{Cl}$ \\
& 2.76 & 1.4 & $\mathrm{Pt}$
\end{tabular}


TABLE 3

Average Au-Au Coordination Number for Supported Au Samples and Percentage of Total Au Present in the Metallic Phase, $M$, for Supported Au and Pt Preparations

\begin{tabular}{ccc}
\hline Sample & $\begin{array}{c}\text { Av coordina- } \\
\text { tion No. of } \\
\text { Au and Pt }\end{array}$ & $M(\%)$ \\
\hline A 1241 & 10.4 & 44 \\
A 1141 & 12.0 & 41 \\
A 1211 & 7.8 & - \\
Cluster \\
$\quad(5.8 \AA$ diam $)$ & 1.7 & - \\
Pt_SiO & 9.7 & 14 \\
\hline
\end{tabular}

measurement of the particulate phase by $\mathrm{X}$-ray diffraction was carried out on a severely sintered A 1141 sample $\left(700^{\circ} \mathrm{C}\right.$, $3 \mathrm{hr}, 1 \mathrm{~atm}$, air). A quantitative X-ray analysis of the amount of metallic Au was performed by the internal standard method. The relative intensities of the diffraction lines were determined from microphotometric traces of Debye-Scherrer patterns. The internal standard was $\mathrm{CaF}_{2}$. The resulls are reporled in Table 4 . In the last column of Table 4 , the ratios between intensities of the sintered and fresh sample are reported. The ratio clearly shows that in the sintered A 1141 sample the content in metallic $\mathrm{Au}$ was almost $30-35 \%$ by weight higher than in the original A 1141 sample. This is taken to correspond to the amount of dispersed $\mathrm{Au}$ which was not in the metallic phase before sintering. This value is in fairly good agreement with the data found by means of the EXAFS analysis.

We conclude that in the two preparations, A 1211, A 1141, and in Pt- $\mathrm{SiO}$, Au and Pt were present in two distinct phases: (a) microparticle, structurally similar to metallic $\mathrm{Au}$ and $\mathrm{Pt}$ and (b) atomically dispersed or in two dimensional clusters. Assuming a cluster of $5.8 \AA$ diameter made out of 7 atoms (a center atom surrounded by 6 atoms in the same plane) it is casily shown that the total coordination number for nonmetallic coordination shown in Table 2 for Au may be fully accounted for.

If we examine closely the nature of the Au dispersed phase in supported A 1241, A 1211 (both $\mathrm{MgO}$ supported), it is realized that the short bond distance (1.77 and $1.61 \AA$ ) does not represent a simple replacement of $\mathrm{Mg}$ by $\mathrm{Au}$ in $\mathrm{MgO}$. In fact, the $\mathrm{Mg}-\mathrm{O}$ bond distance in $\mathrm{MgO}$ is $2.11 \AA$ (9). An Au atom substitutionally placed at the center of the $(100)$ or of the unit cube of $\mathrm{Mg}$ would have neighbors at 1.49 and $1.82 \AA$, respectively. To identify definitively the positions of $\mathrm{Au}$ in the MgO lattice it would be necessary to carry out other quantitative measurements of the effect of temperature on bond distance. In the $\mathrm{Al}_{2} \mathrm{O}_{3}$ supported sample (A 1141) the situation is more clear. In fact, the peak at $2.00 \AA$ is appropriate for atoms in an octahedral hole. Information on $\mathrm{Au}$ location is important, since $\mathrm{Au}$ reactivity in chemisorption and catalysis is expected to depend upon the effect of the matrix crystal ficld on the $\mathrm{Au}$ clectronic levels.

The observed values of the $L_{\text {III }}$ edge shifts, which are surprisingly small in relation to the $K$ series (III), are collected in Table 5 .

The large experimental error and the complex coordination of the samples make a quantitative interpretation of the shifts

\section{TABLE 4}

Relative X-Ray Diffraction Intensities of Fresh and Sintered A 1141 Samples

\begin{tabular}{cccc} 
Au & $\begin{array}{c}\text { Relative } \\
\text { fresh }\end{array}$ & $\begin{array}{c}\text { Intensity }^{a} \\
\text { sintered }\end{array}$ & $\begin{array}{c}\text { Fresh/ } \\
\text { sintered }\end{array}$ \\
\hline$(111)$ & 79 & 109 & 0.72 \\
$(200)$ & 33 & 49 & 0.67 \\
$(220)$ & 26 & 38 & 0.68 \\
$(311)$ & 19 & 32 & 0.59 \\
\hline
\end{tabular}

a Peak intensities averaged from two $X$-ray diffraction experiments made on two different specimens of the same sample. 
TABLE 5

Chemical Shifts of $L_{\text {III }}$ Absorption Edge, $E$, for $\mathrm{Au}$ and Pt Materials

\begin{tabular}{ll}
\hline \multicolumn{1}{c}{ Material } & $E(\mathrm{eV})$ \\
\hline $\mathrm{Au}$ & $0.0 \pm 1.5$ \\
$\mathrm{HAuCl}_{4} \cdot 3 \mathrm{H}_{2} \mathrm{O}$ & -3.0 \\
$\mathrm{Au}_{2} \mathrm{O}_{3}$ & -3.4 \\
$\mathrm{~A} 1241_{\mathrm{A} 1141}$ & -0.8 \\
$\mathrm{~A} 1211$ & -2.0 \\
$\mathrm{Pt}$ & -0.5 \\
$\mathrm{PtCl}_{2}$ & $0.0 \pm 1.5$ \\
$\mathrm{PtO}_{2}$ & +1.5 \\
$\mathrm{Pt}_{\mathrm{SiO}}$ & +0.9 \\
\hline
\end{tabular}

impossible. The interesting and yet unexplained result is their negative values. Among the Au samples, A 1141 is unique in having a much higher shift than A 1241 and $A$ 1211. It is tempting to relate the difference in the chemical shift to binding with the support. To illuminate this point we have computed the charge that appears at the periphery of an absorption atom of valence $z$ as a result of being chemically bonded to $n$ near neighbor atoms by means of a chemical bond of degree of covalence $C$. This charge, called the effective coordination charge, $\eta$, is given by $\eta=z$ - Cn (10). A smooth correlation has been reported between $\eta$ and the $L_{\text {III }}$ absorption edge of $\mathrm{Nd}$ in several salts (11). $C$ was calculated from the expression $C=1-i$,

TABLE 6

Chemical Valence, $z$, Coordination, $n$, and Effective Coordination Charge $\eta$ for Au Preparations

\begin{tabular}{|c|c|c|c|c|c|}
\hline \multirow{3}{*}{$\begin{array}{l}\text { Material } \\
\mathrm{Au}_{2} \mathrm{O}_{3}\end{array}$} & \multirow{3}{*}{$\begin{array}{c}\text { Ion } \\
\mathrm{Au}^{3+} \\
\mathrm{O}^{2-}\end{array}$} & \multicolumn{3}{|c|}{$\begin{array}{c}z X_{\mathrm{A}}-X_{\mathrm{B}} n \\
(\mathrm{eV} / 2.8)\end{array}$} & \multirow{3}{*}{$\frac{\eta}{+1.05}$} \\
\hline & & 3 & 1.80 & 4 & \\
\hline & & 2 & 3.50 & & \\
\hline \multirow[t]{2}{*}{$\mathrm{HAuCl}_{4} \cdot 3 \mathrm{H}_{2} \mathrm{O}$} & $\mathrm{A}^{8+}$ & 3 & 1.80 & 4 & -0.05 \\
\hline & $\mathrm{Cl}^{-}$ & 5 & 2.83 & & \\
\hline \multirow[t]{4}{*}{ A 1141} & $\mathrm{~A}^{3+}$ & 3 & 1.42 & 6 & +0.08 \\
\hline & $\mathrm{O}^{2-}$ & 2 & 3.50 & & \\
\hline & $\mathrm{Au}^{1+}$ & 1 & 5.42 & 6 & -1.03 \\
\hline & $\mathrm{O}^{2-}$ & 2 & 3.50 & & \\
\hline
\end{tabular}

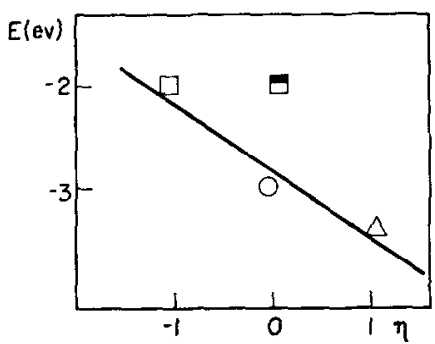

Fig. 13. Effective coordination charge, $\eta$, and chemical shift $E$, for the $L_{\text {III }}$ absorption edge in A 1141 and $\mathrm{Au}$ compounds, (ㅁ) A 1141 (as $\mathrm{Au}^{+}$), (E) A 1141 (as $\mathrm{Au}^{3+}$ ), (O) $\mathrm{HAuCl}_{4} \cdot 3 \mathrm{H}_{2} \mathrm{O},(\triangle)$ $\mathrm{Au}_{2} \mathrm{O}_{3}$.

where $i$ is given by $(9)$ :

$$
i=\exp \left[\frac{1}{4}\left(X_{\mathrm{A}}-X_{\mathrm{B}}\right)^{2}\right],
$$

where $X_{\mathrm{A}}, X_{\mathrm{B}}$ are the electronegativities of the atoms. We have carried out these calculations for $\mathrm{Au}_{2} \mathrm{O}_{3}, \mathrm{HAuCl}_{4} \cdot 3 \mathrm{H}_{2} \mathrm{O}$ and A 1141. The results of the calculations are reported in Table 6 . Using the values of the $L_{\text {III }}$ absorption edge shifts, $E$, reported in Table 5, the correlation between $E$ and $\eta$ is presented in Fig. 13. Considering the semiempirical character of the correlation, and the experimental error in the quantitative determination of the edge shift, a fairly linear relationship is obtained. Interestingly, the correlation points to $\mathrm{Au}^{+}$ as the most likely charge state of $\mathrm{Au}$ atomically dispersed in the $\mathrm{Al}_{2} \mathrm{O}_{3}$ matrix. Support for this conclusion may also be found in the fact that $\mathrm{Au}^{3+}$ in alkali metal oxoaurates has been found to have a coordination number of 4 (12), inconsistent with the values reported in Table 2 .

In previous studies on supported $\mathrm{Au}$ catalysts by means of Mössbauer spectroscopy (13), it was discovered that isomer shifts more negative than metallic $\mathrm{Au}$ and $\mathrm{Au}^{3+}$ (in the starting salt) were obtained with supported Au catalysts, when treated under selected conditions of time-temperature-atmosphere. Essentially, tracing the Au isomer shift during preparative conditions, it was found that treatment at $370^{\circ} \mathrm{C}$ for $3 \mathrm{hr}$ in air produced an isomer 
shift more negative than that corresponding to metallic Au. Such a shift resulted from an $s$ electron density at the nucleus lower than that of $\mathrm{Au}$ metal, and it was suggested that it may have represented $A u$ in strongly electronegative environment. This, of course, is also the conclusion drawn for the present $\mathrm{Au}$ preparations via EXAFS analysis. Furthermore, it seems reasonable to suggest that $\mathrm{Au}^{+}$, obtained by removal of one $s$ electron from the $d^{10} s$ electronic configuration of $\mathrm{Au}$, should have a lower $s$ electron density than the metal and, consequently, should show Mössbauer isomer shift at more negative velocities. It seems, therefore, that the model of supported $\mathrm{Au}$, which emerges from the present results is consistent with and supported by results obtained by means of Mössbauer spectroscopy.

\section{CONCLUSION}

The EXAFS analysis of supported Au samples has confirmed the presence of highly dispersed $\mathrm{Au}$ (dissolved phase) and of large metal particles (particulate phase). The former consisted of $\mathrm{Au}$ atomically dissolved or present in small, flat clusters. Despite the structurally complex nature of the supported samples fine chemical and structural aspects emerged; the description of the environment of the Au atoms was obtained with a richness of details not achieved before and unmatched by other techniques employed for characterization of supported metal samples.

The results obtained pose several questions on the nature and properties of supported metal catalysts. What are the factors involved in the stabilization of atomically dispersed $\mathrm{Au}$ and $\mathrm{Pt}$ in $\mathrm{Al}_{2} \mathrm{O}_{3}$, $\mathrm{MgO}$, and $\mathrm{SiO}_{2}$ ? What is the nature of the Au-support electronic interaction, which tends to favor a lower valence state of $\mathrm{Au}$ ? What is a realistic model for the $\mathrm{Au}-\mathrm{Al}_{2} \mathrm{O}_{3}, \mathrm{Au}-\mathrm{MgO}$ and $\mathrm{Pt}-\mathrm{SiO}_{2}$ "solid solution"? What are the preparative factors which control the ratio between the disperse and the particulate (microparticle) phase? What is the relative chemical reactivity of the two phases? Are all the $\mathrm{Au}$ atoms of the dissolved phase in a nonporous support (MgO) available to gas adsorption? This is an important question in calculations of metal dispersion by gas adsorption and reaction rates per unit metal surface area. In the context of the present work, the EXAFS technique will most likely play a leading role in clarifying these and related problems.

\section{ACKNOWLEDGMENT}

We thank Mr. M. Calcaterra and Mr. V. Bozzola for the X-ray diffraction measurements and Professor P. Corradini for helpful suggestions.

\section{REFERENCES}

1. Cha, D. Y., and Parravano, G., J. Calal. 18, 200 (1970).

2. Parravano, G., J. Catal. 18, 320 (1970).

3. Farbenfabriken Bayer, A. G., Belgian Pat. No. $627,888,1967$.

4. Lytle, F. W., Sayers, D. E., and Stern, E. A., Phys. Rev. B 11, 4825, 4836 (1975); Lytle, F. W., Sayers, D. E., and Moore, E. B., Appl. Phys. Lett. 24, 45 (1974).

5. Hoekstra, H. R., and Siegel, S., Inorg. Chem. 7, 141 (1968).

6. Wyckoff, R. W. G., "Crystal Structures," Vol. 1, p. 15. Wiley (Interscience), New York, 1960.

7. Mueller, O., Newnham, R. E., and Ray, R., J. Inorg. Nucl. Chem. 31, 2966 (1969).

8. Lytle, F. W., Sayers, D. E., and Stern, E. A., Phys. Rev. Lett., submitted.

9. Pauling, L., "The Nature of Chemical Bond." Cornell Univ. Press, Ithaca, N. Y., 1948.

10. Batsanov, S. S., "Electronegativity of Elements and Chemical Bonds." Novosibirsk, 1962, USSR Academy of Science Publisher.

11. Ovsygannikova, I. A., Batsanova, S. S., Nasonova, L. I., Batsanova L. R., and Nakrasov, E. A., Bull. Acad. Sc. USSR, Phys. Ser. 31, 936 (1967).

12. Hoppe, R., and Arend, K-H., Z. Anorg. Allg. Chem. 314, 4 (1962).

13. Delgass, W. N., Boudart, M., and Parravano, G., I. Phys. Chem. 72, 3563 (1968). 